Fifth International Conference on Sustainable Construction Materials and

Technologies. http://www.claisse.info/Proceedings.htm

\title{
DURABILITY OF MECHANICAL PROPERTIES OF GFRP REBARS EXPOSED TO SEAWATER
}

\author{
Alvaro Ruiz Emparanza ${ }^{1}$, Francisco De Caso Y Basalo², Raphael Kampmann ${ }^{3}$, Pedro
} Rodrigues de Castro Jalles ${ }^{4}$, Antonio Nanni ${ }^{5}$

${ }^{1} 1251$ Memorial Dr, Coral Gables, FL 33146; axr1489@ miami.edu; University of Miami, Department of Civil, Architectural, and Environmental Engineering

${ }^{2} 1251$ Memorial Dr, Coral Gables, FL 33146; fdecaso@ miami.edu; University of Miami, Department of Civil, Architectural, and Environmental Engineering

32525 Pottsdamer St, Tallahassee, FL 32310; kampmann@eng.famu.fsu.edu; Florida A\&M University - Florida State University, Department of Civil \& Environmental Engineering

${ }^{4} 1251$ Memorial Dr, Coral Gables, FL 33146; p.jalles@ umiami.edu; University of Miami, Department of Civil, Architectural, and Environmental Engineering

51251 Memorial Dr, Coral Gables, FL 33146; nanni@ miami.edu; University of Miami, Department of Civil, Architectural, and Environmental Engineering

\section{ABSTRACT}

A continued process exists to implement innovative materials to enhance the sustainability and durability of the built infrastructure. Technologies developed over the last two decades have facilitated the use of glass fiber reinforced polymer (GFRP) composites as internal reinforcement bars (rebars) for concrete structures, which have proven to be an alternative to traditional steel reinforcement due to significant advantages, such as magnetic transparency and, most importantly, corrosion resistance, equating to durability and structural life extension.

This study evaluated the durability of three different commercially available and most commonly used GFRP rebar types for resistance to aggressive environments, such as those experienced in coastal areas. In total, 216 specimens were exposed to seawater, at various temperatures $\left(23,40\right.$ and $60^{\circ} \mathrm{C}$ ) for different time periods (60 and 120 days). The durability of these GFRP rebars was assessed by testing five different physiomechanical properties, including: tensile strength, modulus of elasticity, transverse and horizontal shear strength, and bond-strength to concrete.

Preliminary results show that the durability of the GFRP rebars after being exposed to seawater at different temperatures, varies considerably among the three different rebar types. Among the tested physio-mechanical properties, tensile strength suffered the highest degradation. 


\section{INTRODUCTION}

The built infrastructure continues to deteriorate due to the increasing traffic and rising environmental impacts. Corrosion of steel reinforcement is one of the main deterioration mechanisms that affects reinforced concrete structures (Portland Cement Association, 2002), which significantly reduces the service life of civil structures. This effect is intensified for infrastructure built in aggressive environments; for instance, coastal areas where structures are exposed to saltwater. Taking into account that 123.3 million people (38\% of U.S. population) live in coastal regions (National Oceanic and Atmospheric Administration - Department of Commerce and U.S. Census Bureau, 2013), an urgent need exists to develop alternative materials that add resilience to the infrastructure. The use of more durable materials will result in savings due to high repair costs related to the corrosion of the steel reinforcement. In fact, in the United States, 54,007 bridges ( $9.1 \%$ of the nation's bridges) were considered structurally deficient in 2016, with a repair and rehabilitation cost estimation of $\$ 128$ billion (American Society of Civil Engineers, 2016).

In the last three decades, the use of glass fiber reinforced polymer (GFRP) rebars has increased worldwide (Ruiz Emparanza et al., 2017b), becoming a viable alternative to steel for reinforced concrete structures. These composite materials are made from longitudinally aligned fibers, embedded in a resin matrix. The fibers are responsible for carrying the load while the resin binds the fibers together, which guarantees load transfer among the individual fibers and protects them (Nanni et al., 2014). These rebars are globally produced, using 'pultusion' processes, and offer various advantages compared to steel rebars: the main benefit is the extended durability but other advantages include high tensile strength (2-3 times higher than steel) and lightweight (1/4 of the weight of the steel).

Because an extended durability is assumed to be the key benefit of this technology and not much data for long-term applications for civil structures in harsh environments is available, research is needed to assess this property and to address it for code implementation and provisions, towards a more efficient design of concrete structures reinforced with alternative GFRP reinforcement. Many research projects exist, which evaluated the durability of GFRP rebars exposed to different solution, such as high $\mathrm{pH}$ (simulating the high alkalinity of the pore solution of concrete), tap water (to check the effect of moisture in submerged applications for example), acid and de-ionized water (conditions experienced in water treatment plants), etc (Chen et al., 2006; Dejke and Tepfers, 2001; Robert et al., 2009; Wu et al., 2014). These research projects mainly focused on retention of tensile properties for the rebars after exposure to the listed aging solutions.

The novelty of this research project was two-fold: (i) accelerated aging was accomplished by exposing naked rebars to circulating seawater taken directly from the ocean, and (ii) not only the tensile strength of the rebars was evaluated, but also the modulus of elasticity, the horizontal and transverse shear strength, and the bond-toconcrete strength. In addition, because the GFRP rebar market is diverse (Ruiz Emparanza et al., 2017a), three different rebar types with distinct features were 
selected, to provide a broader insight. A relative comparison between three different products can therefore aid manufacturers during product improvement, based on performance data of different rebar systems. However, the correlation between the durability results obtained from the accelerated conditioning protocols and the field exposure, was not covered in the paper.

\section{METHODOLOGY}

The experimental program consisted of testing three commercially available GFRP rebar types (see Figure 1), before and after exposure to seawater. All tested rebars had a nominal diameter of $10 \mathrm{~mm}$ and were made from the same fiber (EC-R Glass) and resins type (Vinyl-Ester). However, the manufacturing process varied and they all had different surface enhancements; critical for the bond-to-concrete behavior (Ruiz Emparanza et al., 2018).

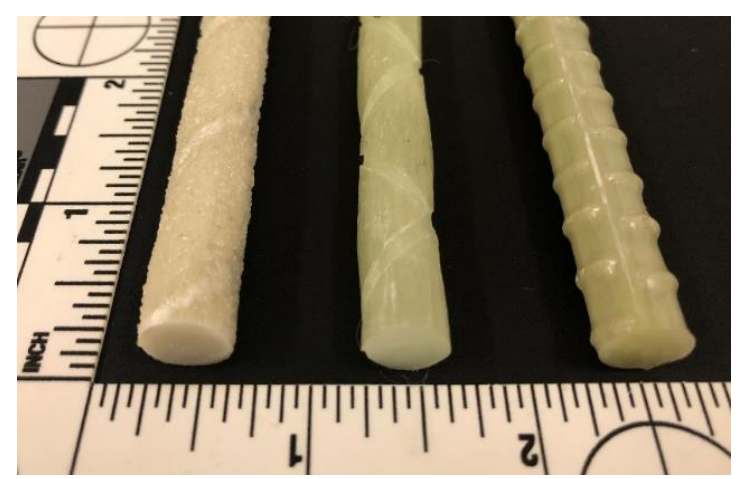

Figure 1. GFRP rebar types A, B, and C, from left to right

For both unexposed and exposed samples, five different physio-mechanical properties of the rebars were tested: tensile strength, modulus of elasticity, transverse and horizontal shear strength, and bond-to-concrete strength. For every property, virgin and condition rebar type, three specimens were tested. Table 1 shows the test matrix for the exposed samples.

Table 1. Test matrix for exposed samples

\begin{tabular}{|c|c|c|c|c|}
\hline $\begin{array}{c}\text { Rebar } \\
\text { type }\end{array}$ & $\begin{array}{l}\text { Temp. } \\
{ }^{\circ} \mathrm{C}\end{array}$ & $\begin{array}{c}\text { Duration } \\
\text { Days }\end{array}$ & Property & Test Method \\
\hline $\begin{array}{l}\text { A } \\
B \\
C\end{array}$ & $\begin{array}{l}23 \\
40 \\
60\end{array}$ & $\begin{array}{c}60 \\
120\end{array}$ & $\begin{array}{l}\text { Tensile Strength } \\
\text { Modulus of Elasticity } \\
\text { Transverse Shear Strength } \\
\text { Horizontal Shear Strength } \\
\text { Bond-Strength to concrete }\end{array}$ & $\begin{array}{l}\text { ASTM D7205 } \\
\text { ASTM D7617 } \\
\text { ASTM D4475 } \\
\text { ASTM D7913 }\end{array}$ \\
\hline
\end{tabular}


The aging of the rebars was accomplished via accelerated conditioning protocols (ACP), by exposing the rebars to seawater at different temperatures $\left(23,40\right.$ and $\left.60^{\circ} \mathrm{C}\right)$ and dissimilar exposure times (60 and 120 days). The rebars were exposed naked in tanks, which circulated seawater directly taken from Key Biscayne (Florida), as seen in Figure 2. The only specimens for which the rebars was not exposed directly to the aging solution were the bond samples: in this case a concrete cube (200 mm long sides) was cast around one of the ends of the rebar, prior to being submerged in seawater.
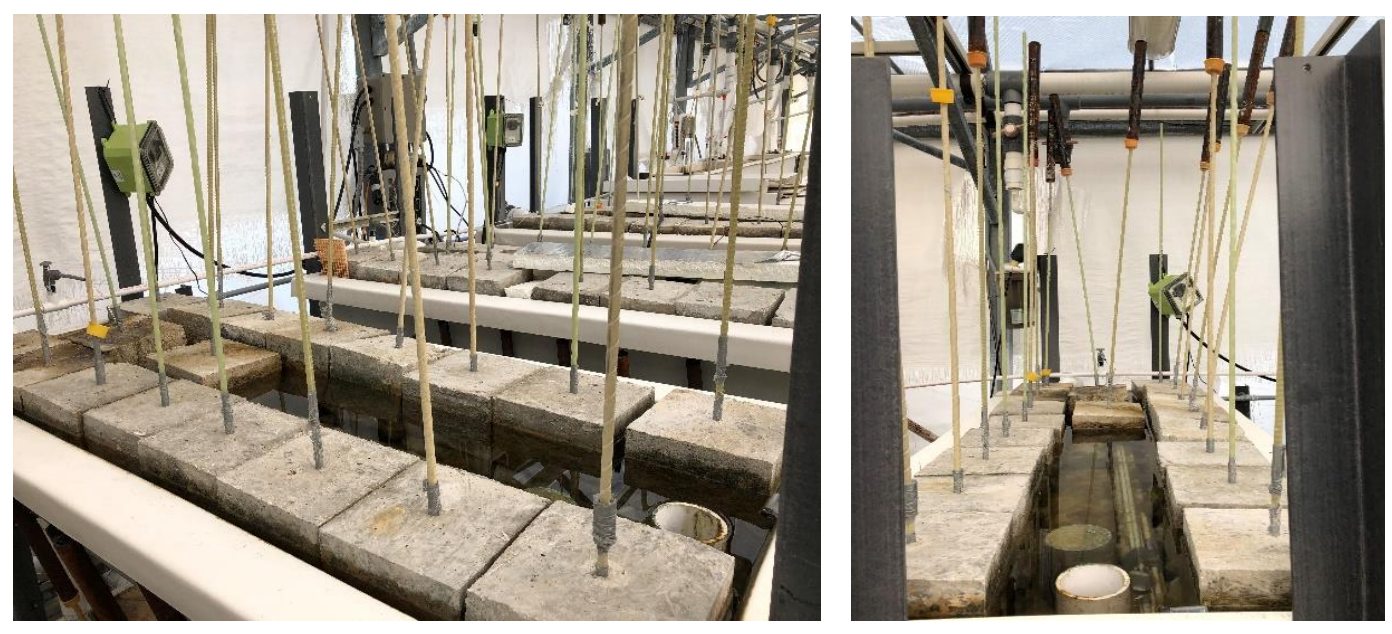

Figure 2. Exposure of the GFRP rebar samples to seawater

\section{Specimen Preparation}

The specimen preparation for each type of test was done according to the corresponding ASTM standards, listed in Table 1. The preparation of the specimens used to test the transverse shear strength consisted of cutting the rebars to $230 \mathrm{~mm}$ while the samples for horizontal shear were cut to a length of 6 times the diameter $(60 \mathrm{~mm})$. The preparation of the tensile and bond specimens, however, was more extensive: after the rebars were cut to length (1000 $\mathrm{mm}$ for tensile and $1700 \mathrm{~mm}$ for bond), protective anchors were installed at the end of the samples (on both ends for tensile specimens and on one end for bond specimens). The anchorage system was formed by a $300 \mathrm{~mm}$ long steel pipe filled with expansive grout and its objective was to protect the rebar from destructive lateral stresses during griping because GFRP rebars are weak in the transverse direction compared to the longitudinal one. Finally, for the bond specimens, the side of the rebar without an anchor was cast in a concrete cube with $200 \mathrm{~mm}$ long sides. Within the $200 \mathrm{~mm}$ cube length, only a bonded length of 5 times the rebar diameter $(50 \mathrm{~mm})$ was in contact with the concrete, while the remaining length $(150$ $\mathrm{mm}$ ) was shielded. The concrete used for the preparation of the bond specimens was the standard FDOT 'Type II 4500 Bridge Deck', with a 28-day compressive strength of $37.20 \mathrm{MPa}$ (Standard deviation of $0.67 \mathrm{MPa}$ and coefficient of variation of $1.8 \%$ ). 


\section{Testing Procedure}

Each rebar property was determined by following the pertinent ASTM standards. All testing was displacement controlled, and the test rates for transverse and horizontal shear, and bond tests were $1.3 \mathrm{~mm} / \mathrm{min}$, while the tensile test specimens were tested at a rate of $2 \mathrm{~mm} / \mathrm{min}$. As per ASTM, for transverse and horizontal shear tests, the crosshead displacement and the load were recorded. For the tensile tests, in addition to the load, a $100 \mathrm{~mm}$ long extensometer was used to record the strain, which was needed to determine the modulus of elasticity. Finally, the instrumentation used for the bond tests included three LVDTs in addition to the load cell: two at the loaded-end and on at the free-end, as specified by ASTM D7913 (ASTM, 2014), to measure both the freeend and loaded-end slippages. Figure 3 shows the test setup of the different tests that were run for this research project.

In total, 36 tests were conducted to characterize the virgin material, whereas 216 tests were performed to assess the durability of the three types of rebars exposed to seawater.
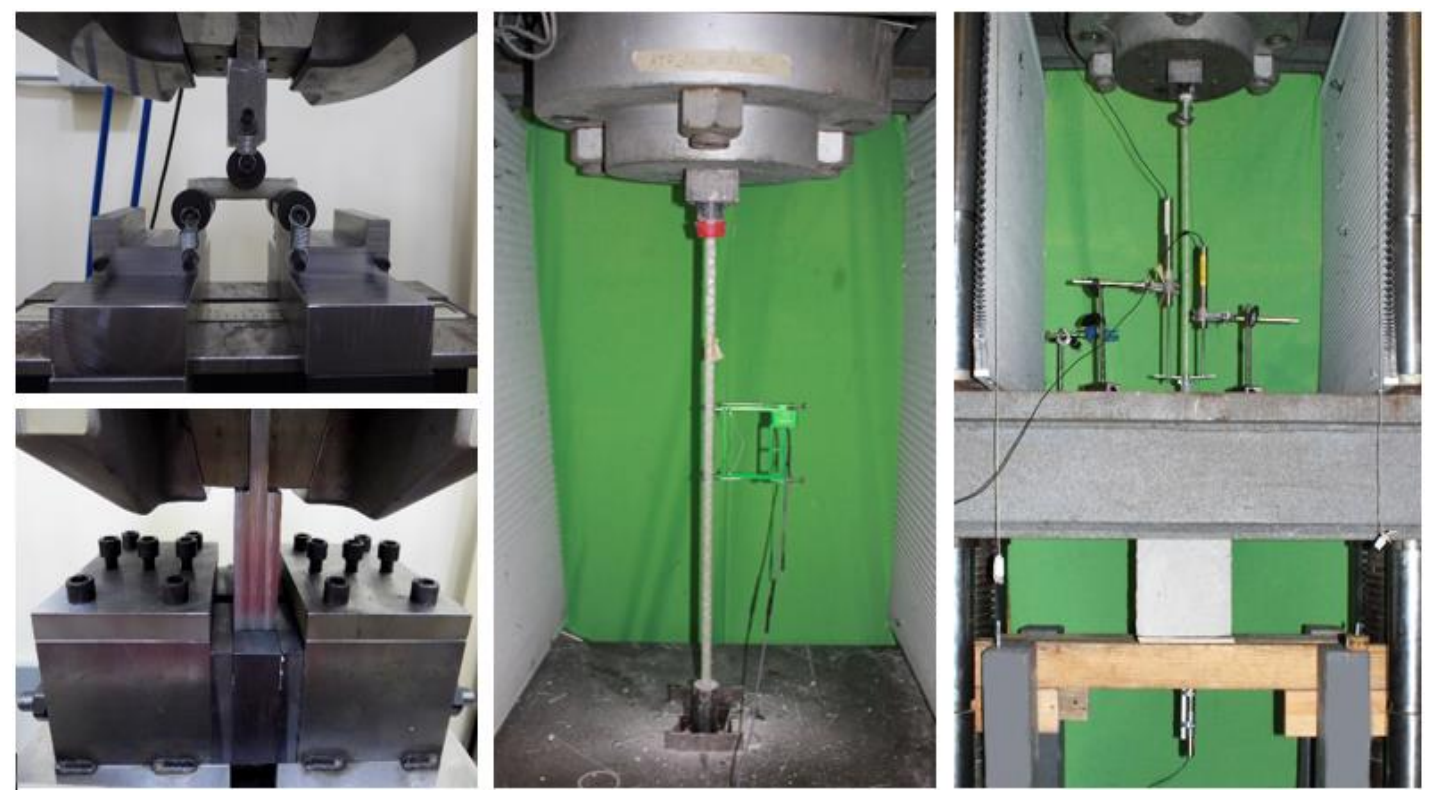

Figure 3. Horizontal shear test (top left), transverse shear test (bottom left), tensile test (center), and bond test (right)

\section{RESULTS AND DISCUSSION}

Every test was completed according to the corresponding ASTM methods listed in Table 1. These standards were also followed when analyzing the obtained results. In Table 2, the peak average nominal values of the five tested physio-mechanical properties are summarized for the three types of rebars in the virgin state. These stress values were calculated based on the nominal area 
Table 2. Benchmark nominal peak average values (MPa) and coefficients of variance

\begin{tabular}{|c|c|c|c|c|c|c|c|c|c|c|}
\hline & \multirow{2}{*}{\multicolumn{2}{|c|}{$\begin{array}{l}\text { Tensile } \\
\text { Strength }\end{array}$}} & \multirow{2}{*}{\multicolumn{2}{|c|}{ E-Modulus }} & \multirow{2}{*}{\multicolumn{2}{|c|}{$\begin{array}{l}\text { Transverse } \\
\text { Shear } \\
\text { Strength } \\
\end{array}$}} & & & & \\
\hline \multirow{2}{*}{$\begin{array}{l}\text { Rebar } \\
\text { type }\end{array}$} & & & & & & & \multicolumn{2}{|c|}{$\begin{array}{l}\text { Horizontal } \\
\text { Shear } \\
\text { Strength } \\
\end{array}$} & \multicolumn{2}{|c|}{$\begin{array}{c}\text { Bond } \\
\text { Strength }\end{array}$} \\
\hline & Avg. & $\mathrm{CoV}$ & Avg. & $\mathrm{CoV}$ & Avg. & $\mathrm{CoV}$ & Avg. & $\mathrm{CoV}$. & Avg. & $\mathrm{CoV}$ \\
\hline & $\mathrm{MPa}$ & $\%$ & $\mathrm{MPa}$ & $\%$ & $\mathrm{MPa}$ & $\%$ & $\mathrm{MPa}$ & $\%$ & $\mathrm{MPa}$ & $\%$ \\
\hline $\mathrm{A}$ & 953.8 & 5.5 & 51570 & 5.1 & 212.4 & 4.8 & 42.9 & 7.7 & 18.4 & 5.0 \\
\hline B & 830.1 & 6.6 & 61220 & 3.2 & 157.0 & 7.5 & 43.7 & 5.9 & 18.7 & 7.7 \\
\hline $\mathrm{C}$ & 982.5 & 4.3 & 54570 & 6.0 & 211.2 & 2.6 & 50.3 & 5.6 & 22.3 & 3.8 \\
\hline
\end{tabular}

It can be seen that the properties of the different rebar types vary significantly. However, all of them reached the minimum strength values defined by the current standard specification for GFRP rebars, ASTM D7957 (ASTM, 2017).

Rebars taken from the same production lot as those tested for benchmark values where then exposed to seawater and tested after 60 and 120 days. Figure 4 shows the retention of the five different properties after exposure at 23,40 and $60^{\circ} \mathrm{C}$. These retention values were calculated by comparing the average peak values after exposure to the benchmark values (obtained for the virgin materials). Therefore, the presented values indicate how much of the initial capacity is retained after a certain aging process.

In general, from the graph in Figure 4, it can be inferred that the exposure at $60^{\circ} \mathrm{C}$ was the most aggressive within the three evaluated temperatures, showing overall lower retention values: minimum retention of about $80 \%$ was found for temperatures of 23 and $40^{\circ} \mathrm{C}$, while retention values as low as $60 \%$ for exposure at $60^{\circ} \mathrm{C}$ were recorded. When comparing the three types of rebars, it can be seen, that Type B rebars showed the lowest deterioration values (max of $15-20 \%$ ) throughout all exposure conditions, whereas type A suffered the highest degradation (up to 40\%). Type $\mathrm{C}$ rebars, however, show comparable results to Type B.

After comparing the different physio-mechanical properties and their retention over time, it was seen that the most affected property was the tensile strength, with up to $40 \%$ of reduction after 120 days at $60^{\circ} \mathrm{C}$. These values were higher than the ones found in literature, where Robert and Benmokrane (2013) saw a deterioration of $15 \%$ after exposing the rebars to a saline solution at $50^{\circ} \mathrm{C}$. The difference can be attributed to the different rebar types that were tested, and most importantly, to the lower temperature used for the accelerated aging $\left(50^{\circ} \mathrm{C}\right.$ compared to $\left.60^{\circ} \mathrm{C}\right)$. 


\section{60 days 120 days}
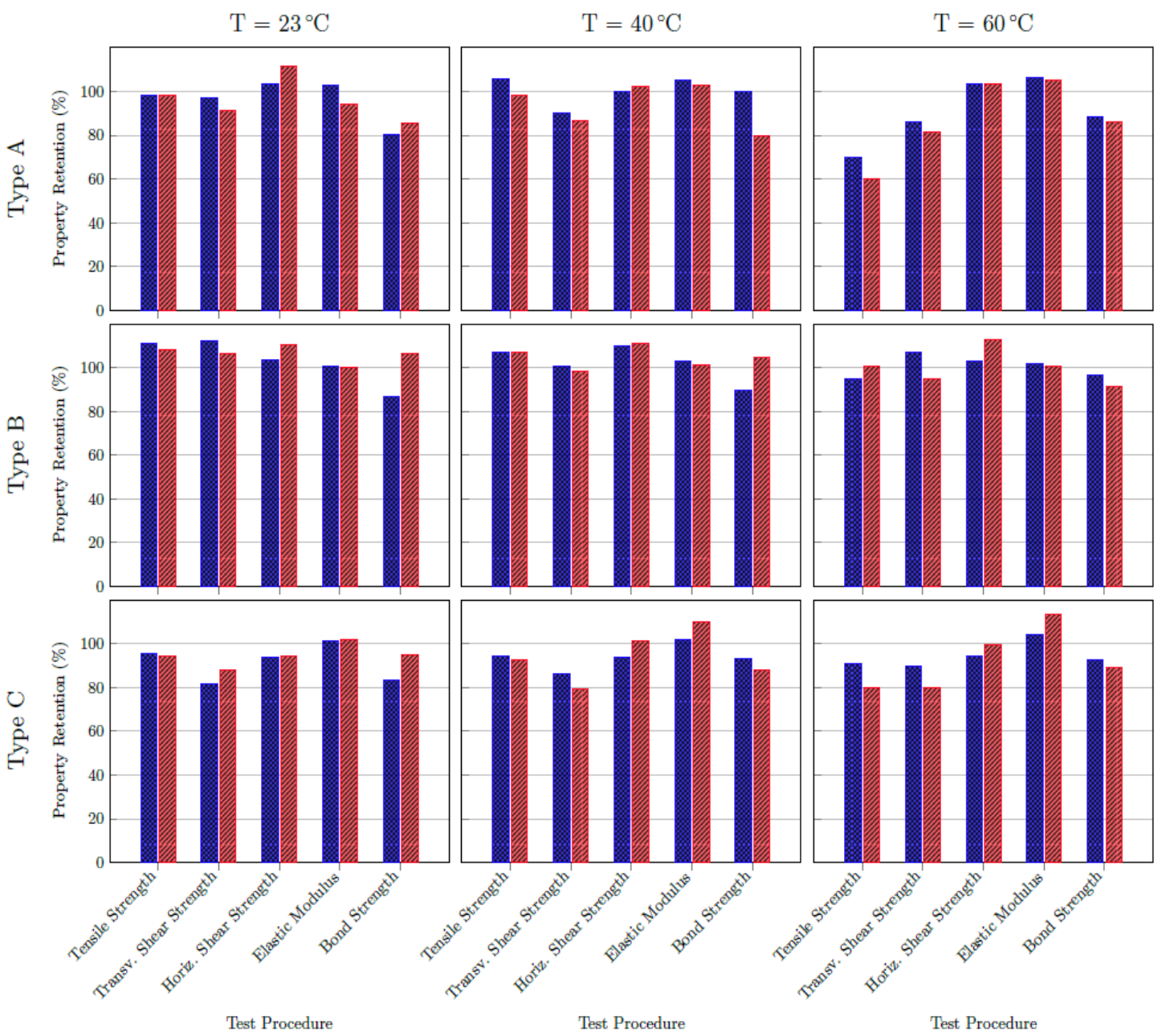

Figure 4. Strength retention of GFRP rebars after being exposed to seawater

The next most affected properties were bond and transverse shear strength, with decrease in strength of up to about $20 \%$. Horizontal shear strength and the modulus of elasticity, however, were almost not altered by the aging process, in some cases those properties even showed increasing values (these low increases can be explained by the existing variance of the results obtained - see Table 2). The low deterioration effect on the modulus of elasticity was also reported by other researchers in the literature, who conveyed maximum degradation values lower than 5\% after comparable aging processes (Al-Salloum et al., 2013; Robert and Benmokrane, 2013). This was attributed to analogous reduction of tensile strength and strain: since the modulus of elasticity describes the change of stress over strain, the effect of the degradation gets canceled when computing the mentioned slope.

In summary, it was seen that the properties that are related to the fibers, such as tensile strength and transverse shear strength (Nanni et al., 2014), were more affected 
compared to the properties in which the resin plays a more dominant role, such as the horizontal shear strength.

\section{CONCLUSIONS}

In this research project, three different rebar types were characterized and their durability in marine environments was assessed. Rebars with a nominal diameter of $10 \mathrm{~mm}$ were used and the aging process was accomplished by exposing the rebars to circulating seawater taken directly from Biscayne Bay in Miami (Florida), for 60 and 120 days, at 23,40 and $60^{\circ} \mathrm{C}$. For this purpose, 5 different physio-mechanical properties were evaluated.

Preliminary results showed that the various tested rebar types have significantly different strength properties, but they all met the minimum requirements defined by ASTM D7957 (ASTM, 2017). In addition, the effect of the aging process was rebar type dependent: Type A rebars show the highest deterioration (up to 40\%) taking into account all the exposure conditions, whereas type B and $\mathrm{C}$ showed the lowest with values of about $15-20 \%$. In any case, the most aggressive exposure for all the rebar types was related to a temperature of $60^{\circ} \mathrm{C}$. Among the different tested physiomechanical properties, the properties mainly related to the capacity of the fibers themselves were the most affected ones: the tensile strength showed the highest deterioration values of up to $40 \%$, followed by transverse shear, which suffered a degradation of about $20 \%$. The retention of the bond strength was very comparable to this last property with around $20 \%$ of capacity reduction after exposure. The horizontal shear (resin related property), however, was almost unaltered. Finally, no degradation was seen in the modulus of elasticity.

These preliminary results show that both the initial properties, as well as, the capacity to withstand salt-rich environments are directly related to the rebar type. In addition, fibers seem to suffer higher deterioration than the resin. However, additional tests should be done to better evaluate the durability, extending the aging time and adding more rebar types to the test matrix. Moreover, tests to determine the properties of the fibers and resin independently, would help to conclude the differences in behavior of different rebar types. Finally, efforts to establish a relationship between the results obtained from the accelerated conditioning protocols and field exposure should be undertaken, since no reliable relationship exists to-date.

\section{ACKNOWLEDGEMENTS}

The authors acknowledge the financial support of the Florida Department of Transportation (FDOT) and the guidance provided by its staff Chase C. Knight, Ph.D. and Steven Nolan, P.E. 


\section{REFERENCES}

Al-Salloum, Y.A., El-Gamal, S., Almusallam, T.H., Alsayed, S.H., Aqel, M., 2013. Effect of harsh environmental conditions on the tensile properties of GFRP bars. Compos. Part B Eng. 45. https://doi.org/10.1016/j.compositesb.2012.05.004

American Society of Civil Engineers, 2016. Infrastructure report card. ASCE News 53, 1-36. https://doi.org/10.1017/CBO9781107415324.004

ASTM International, 2017. ASTM D7957 - Standard Specification for Solid Round Glass Fiber Reinforced Polymer Bars for Concrete Reinforcement. https://doi.org/10.1520/D7957

ASTM International, 2014. ASTM D7913 - Standard Test Method for Bond Strength of Fiber-Reinforced Polymer Matrix Composite Bars to Concrete by Pullout Testing. ASTM-International, West Conshohocken, PA. https://doi.org/10.1520/D7913

Chen, Y., Davalos, J.F., Ray, I., 2006. Durability prediction for GFRP reinforcing bars using short-term data of accelerated aging tests. J. Compos. Constr. 10, 279-286.

Dejke, V., Tepfers, R., 2001. Durability and service life prediction of GFRP for concrete reinforcement, in: Proc., 5th Int. Conf. on Fiber-Reinforced Plastics for Reinforced Concrete Structures (FRPRCS-5). Thomas Telford London, pp. 505516.

Nanni, A., De Luca, A., Zadeh, H., 2014. Reinforced Concrete with FRP Bars. https://doi.org/10.1201/b16669

National Oceanic and Atmospheric Administration - Department of Commerce, U.S. Census Bureau, 2013. National Coastal Population Report - Population Trends from 1970 to 2020. https://doi.org/10.1038/srep26725

Portland Cement Association, 2002. Type and causes of concrete deterioration.

Robert, M., Benmokrane, B., 2013. Combined effects of saline solution and moist concrete on long-term durability of GFRP reinforcing bars. Constr. Build. Mater. 38. https://doi.org/10.1016/j.conbuildmat.2012.08.021

Robert, M., Cousin, P., Benmokrane, B., 2009. Durability of GFRP reinforcing bars embedded in moist concrete. J. Compos. Constr. 13, 66-73.

Ruiz Emparanza, A., De Caso Y Basalo, F., Kampmann, R., Adarraga Usabiaga, I., 2018. Evaluation of the Bond-To-Concrete Properties of GFRP Rebars in Marine Environments. Infrastructures 3, 44.

Ruiz Emparanza, A., Kampmann, R., De Caso y Basalo, F., 2017a. State-of-thepractive of FRP rebar global manufacturing, in: CAMX: The Composite And Advanced Materials Expo. Orlando, Fl. 
Ruiz Emparanza, A., Kampmann, R., De Caso Y Basalo, F., 2017b. State-of-thePractice of Global Manufacturing of FRP Rebar and Specifications, in: ACI Fall Convention. Anaheim, CA.

Wu, G., Dong, Z., Wang, X., Zhu, Y., Wu, Z., 2014. Prediction of Long-Term Performance and Durability of BFRP Bars under the Combined Effect of Sustained Load and Corrosive Solutions. J. Compos. Constr. 19, 4014058. https://doi.org/10.1061/(ASCE)CC.1943-5614.0000517 